\title{
Effects of 6 Weeks Psychological Skill Training on Team Cohesion, Self-confidence \& Anxiety: A Case of Youth Basketball Players
}

\author{
Bülent Okan Miçooğullari ${ }^{1, *}$, Sadettin Kirazci ${ }^{2}$ \\ ${ }^{1}$ Department of Physical Education \& Sports Education, Faculty of Education, Nevsehir Haci Bektaş Veli University, Turkey \\ ${ }^{2}$ Department of Physical Education \& Sports, Faculty of Education, Middle East Technical University, Turkey
}

Copyright $\bigcirc 2016$ by authors, all rights reserved. Authors agree that this article remains permanently open access under the terms of the Creative Commons Attribution License 4.0 International License

\begin{abstract}
The purpose of this study was to examine the impact of a six-week psychological skill training (PST) program that is based on a cognitive-behavioral conceptual framework on team cohesion, confidence, and anxiety of an intact team. Thirty-six male basketball players, 19 athletes for the experimental group and 17 athletes for the control group, aged between 15-16 years old voluntarily participated in this study. For the quantitative part of the study, the Group Environment Questionnaire, Trait Sport-Confidence Inventory, and State-Trait Anxiety Inventory were given during the pre-intervention, post-intervention and follow-up tests. Qualitative methods were also employed in the current study to support validation of the implied PST program. Six players and the coach of both teams were interviewed utilizing a semi-structured interview schedule. Statistical testing within factor analyses of the experimental group reveals a significant difference over time for team cohesion and for self-confidence but no significant difference for anxiety. Moreover, comparisons between the experimental and control groups' results indicate that there is a significant difference between groups. Overall, it is concluded that the experimental team's participation in the PST program affected the team's cohesion levels and the athletes' self-confidence levels positively but there is no significant effect on the athletes' anxiety levels.
\end{abstract}

Keywords Psychological Skill Training Program, Team-cohesion, Self-confidence, Anxiety

\section{Introduction}

Over the past decade, there has been a rapid growth of interest in the mental preparation of athletes. This interest was first reflected in the increased volume of cognitive research in sport psychology and has more recently resulted in integrating various applied "psychological skills" training programs into the traditional training regimens of all competitive sports [1]. Vealey declared that mental preparation is the learning and implementation of traditional cognitive behavioral techniques "with the objective of assisting sports participants in the development of mental skills to achieve performance success and personal well-being" (p. 287) [2]. To observe the effectiveness of any mental preparation plan, it is critical to focus on functional aspects of mental preparation routines such as attaining an ideal cognitive state, developing high self-confidence, controlling mental energy, and sustaining attentional focus to the task [3]. Comprehensive studies in sport psychology literature have supported the effectiveness of PST on improving not only the performance but also personal growth of athletes. Bacon indicated that mental preparation facilitates learning. Additionally, Bacon suggested that once the basics of each mental skill have been learned, they can also be used to help achieve the athletes' other competition and training aims [4].

There are different strategies to reach effective mental preparation. One of the most widely used strategies for mental preparation is psychological skill training (PST) [5, 6]. PST is the systematic learning and practice of psychological skills [7]. PST is a process that relates to the development of daily routine activities and capabilities in sport and exercise [8]. Different psychological skills -abilities- are interrelated components, separately for the purposes of research and training. Standard methods and techniques of PST come from a wide range of sources, particularly those in the areas of general psychology. PST has been utilized by athletes at all levels including elite and Olympic athletes, and the use of certain psychological skills has been approved to differentiate between more successful and less successful athletes. In the earliest step of scientific evaluations trials of PST instructions were performed on individual skills such as physiological arousal, cognitive arousal, mental images, attention, concentration, confidence, goal setting and motivation [7]. The following step included 
the combination of a variety of psychological skills to improve development, implementation and evaluation of PST package programs according to the aim of the practitioner [9]. Comprehensive studies reveal that PST is the most efficient when a combination of psychological skills are used [10,11, 12, 13]. Applications and results of the studies highlight that PST should be designed with three distinct phases: education, acquisition and practice phases [9, 14]. The first phase of a PST program is the education phase, which involves increasing athletes' awareness of the role that psychological skills play in performance and personal growth [3]. In the education phase participants learn the importance of PST and how the skills affect athletic performance. The second phase of PST is the acquisition phase. In this phase the athletes learn how to use and best implement PST methods. Formal sessions are carried out with an instructor that can teach the athlete the relevant methods so that they can then practice them by themselves until they are familiar and experienced with those methods [8]. The last phase is the practice phase during which athletes devote their own time and effort to PST. They must complete training in both competition and practice [15].

Because PST remains is a crucial aspect to the current study, its effectiveness plays a very important role in this research. Comprehensive reviews of psychological skill training literature have supported the effectiveness of PST in improving the performance and personal growth of athletes' $[11,16,17]$. In particular, published studies using either group or single subject research designs were examined. These studies utilized different variables (age, gender, education level, athletes' category, type of sports), evaluated different psychological skills (relaxation, imagery, goal setting, and focusing, cohesion, self-talk, self-confidence, motivation, concentration etc), and ultimately revealed that PST is an effective strategy employed to develop personal growth and achieve excellence in performance [18, 19, 20, $21,22,23,24,25]$

Even though the importance and effectiveness of PST is evident in sport psychology literature, especially according to obvious cultural \& societal differences, to date limited effort has been made in Turkey to examine the impact of a PST program that is framed by cognitive-behaviorism on the various aspects of athletes' lives (sportive and regular) such as team cohesion, anxiety, self-confidence and personal growth. In light of aforementioned information, the purpose of this study was to implement a PST program for athletes and assess its effect on team cohesion, self-confidence and anxiety of youth basketball players.

\section{Methodology}

\subsection{Participants}

Thirty-six male basketball players, 19 athletes for experimental group $(\mathrm{M}=5.79$ and $\mathrm{SD}=1.87$ years of sport experience) and 17 athletes for control group (M=6.00 and
$\mathrm{SD}=2.26$ years of sport experience) aged between 15-16 years old voluntarily participated in this study. None of the participants had previously worked with a psychological training consultant. Participants were selected from two teams in Ankara Youth Basketball league. The teams were selected purposively from the same league category in order to avoid any possible bias between them. At the beginning of the study, each group consisted of 20 athletes but 3 athletes from control group left the club.

\subsection{Measuring Instruments}

2.2.1. Group Environment Questionnaire (Carron, Widmeyer, \& Brawley, 1985)

Group environment questionnaire (GEQ) was used to assess team cohesion level of basketball players. The 18-item GEQ assesses four dimensions of cohesion: individual attractions to the group-social (ATG-S; five items); individual attractions to the group-task (ATG-T; four items); group integration- task (GI-T; five items); and group integration-social (GI-S; four items). Participants respond to each of the 18 statements on a 9-point Likert scale anchored at 1 by strongly disagree and 9 by strongly agree. The original Cronbach's alpha values of the four scales were .70 for (ATG-T/S) and .73 for (GI-T/S). The reliability and validity of the Turkish version of the Group Environment Questionnaire (GEQ) was determined by Öcel [26]. The Cronbach's alpha obtained for total scores and subscales ranged from .79 to .69. Internal consistency values for the present study showed acceptable values of the four scales were ranged between .67 (ATG-T-S) and .78 (GI-T-S).

\subsubsection{Trait Sport-Confidence Inventory (Vealey, 1988)}

Trait Sport-Confidence Inventory (TSCI) was used to assess self-confidence level of basketball players. TSCI is a measure of the degree of certainty athletes usually hold about their ability to succeed in sport. The TSCI is comprised of 13 items measured on a 9- point Likert scale anchored by Low (1) and High (9). Adequate internal consistency (.93) has been reported (Vealey, 1988) and test-retest reliabilities have been shown to be consistently high after one day (.86), one week (.89), and one month (.83) interval. Reliability and validity of the Turkish version of the TSCI was determined by Engür, Tok, Tatar [27] on 16 and 19 year old high school graduate students.

\subsubsection{State-Trait Anxiety Inventory (Spielberger, 1970)}

In the current study, trait anxiety was measured by trait form of the State - Trait Anxiety Inventory (STAI) which includes 20-items [45]. Participants responded to each item according to how they generally feel using a four-point scale ranging from "Almost Never" (1), "Sometimes" (2), "Often" (3), to "Almost Always" (4). The original Cronbach's alpha value for the trait anxiety scale was .83 . Original scale was developed on 982 high school and collegiate students but the scale is reported as reliable (internal consistency 0.80 ) for 
young players by Griciūte and Cibulskaite [22]. Reliability and validity of the Turkish version of the STAI was determined on 1534 youth and adult and its internal consistency reliability was .94 [28]. Cronbach's Alpha for the present study showed acceptable value was .69 .

\subsection{Procedure}

The intervention described here has involved three different psychological skills: anxiety control, self-confidence, and team cohesion (team building). These three psychological skills were selected in the current program because of two factors. Firstly, discussions with coaches of the teams indicated that these three skills are the most lacking ones in many basketball players. Secondly, these skills are particularly important for optimal performance in athletics [7, 9, 29]. Prior to beginning the PST program, written approval was obtained from the Associate Athletic Director of Sport Club. Permission was also obtained from Institutional Review Board of the Middle East Technical University to conduct the study. After explaining the purpose of the study and telling participants they could withdraw at any time, they signed an informed consent form. A demographic information sheet and Group Environment Questionnaire [30] Trait Sport-Confidence Inventory (TSCI) [31] and State-Trait Anxiety Inventory (STAI) [32] were administered to the athletes at a team meeting prior to the beginning of the second half season in order to obtain baseline data and post test after intervention season in order to assess changes in the various measures. The PST program consisted of team building, goal setting, relaxation, imagery, self-talk, pep-talk, converting thoughts, autogenic training, and progressive relaxation techniques.

Overall, six weeks psychological skills program took place during the season. Each skill's processes lasted for two weeks. Weinberg \& Gould's PST program phases (education, acquisition and practice) were pursued to practice psychological skills. Six weeks PST program consisted of twenty four sessions totally. For each psychological skill, eight sessions were conducted. First two sessions of each skill were implemented for education phase. Five sessions were implemented for acquisition phase of PST and one session of program was for practice phase to make corrections and reviews if needed. At the end of 6 weeks of intervention, three follow up tests (GEQ; TSCI and STAI) were applied to athletes within three different time periods. The first follow up test was performed 2 weeks after the end of the intervention; it was decided to perform this test 2 weeks later because the necessary time period for all the processes and applications of one skill (team cohesion, self-confidence and anxiety) was 2 weeks. Since 6 weeks was equal to all intervention program time period which was needed for processes and applications of all the skills, the second follow up test was practiced 6 weeks later. Moreover, the last follow up test was performed 20 weeks later because it was aimed to see the long term effects of applied psychological skill training.

\subsection{Data Analysis}

Descriptive statistics (means and standard deviations) for demographic information and scale scores were calculated. In order to analyze possible changes in the measures for team cohesion skill from pre-season to postseason and follow up tests, a mixed design multivariate analysis of variance (MANOVA) was utilized. In order to analyze possible changes in the measures for self-confidence and anxiety skills from pre-season to postseason and follow up tests, a mixed design analysis of variance (ANOVA) was utilized [33].

\subsection{Qualitative Methodology}

The goal of the adding qualitative analysis to current study was to assist validation of psychological skill training with the feelings and words of athletes and coach.

After conduction of the quantitative processes, to collect qualitative data, follow-up individual interviews were conducted after the third follow up test ( 24 weeks after finishing day of intervention) on a six participant athletes -purposively selected- from out of 19 athletes and the coach of the team. According to qualifications of one on one interview approach each interview was implemented face to face according to qualifications of one on one interview approach. In this approach the researcher asks questions to and record answers from only one participant. One focus of interview was to find out the most useful skill within implemented PST program, and effects of each skill on sport and real life situations according to athletes. Another focus of interview was to understand if the coach perceives any positive effects of PST on individual and team level and whether the coach thinks of having PST in the future or not. Each interview lasted between 25 to 40 minutes. For qualitative analysis, all interviews with athletes and coach were analyzed using the constant comparison approach. Audio-recorded interviews were transcribed and open coding was used to analyze the data divided into segments and then they were scrutinized for commonalities that could reflect codes. Secondly, axial coding grouped the codes therefore connections were made amongst the categories and the subcategories. In this way, similar comments were grouped together to form categories related to the research questions. Finally, selective coding was used to develop the themes which systematically relating it to the other categories [34].

\section{Results}

Obtained descriptive and quantitative results were displayed according to their applied rank.

Descriptive results revealed that experimental group's team cohesion generally improved till the first follow up and after those values were stable while control group's values of team cohesion generally showed slight increase till the first follow up and after that values were stable or decreased 
(Table 1). Self-confidence mean values of experimental group results showed that they reached the highest value at third follow up test while -unlooked for- self-confidence of control groups showed enhancement from pre-test to first follow up test and arrived the peak point and after that it showed slight decrease situation. On the last rank; Anxiety scores of experimental group did not make any significant changes from pre-test to third follow up test but anxiety of control group slightly increased from pre-test to third follow up test.

First ranked skill of the PST was team cohesion and to test the effects of the PST on it, a mixed design Multivariate Analysis of Variance (MANOVA) was conducted. The results of the mixed design MANOVA (5 (time) x 2 (group)) for the subscales of GEQ (ATG-T, ATG-S, GI-T, and GI-S) revealed significant time $\mathrm{x}$ group interaction effects; Wilks' Lambda $=.27 . F_{(16,19)}=3.25 \mathrm{p}<.05$. MANOVA also revealed meaningful time; Wilks' Lambda $=.21$. $F_{(16,19)}=4.40, \mathrm{p}<.05$ and group main effects; Wilks' Lambda $=.39 . F_{(16,19)}=11.81, \mathrm{p}<.05$.

Used mixed design MANOVA results of time $\mathrm{x}$ group interaction, time and group main effects were meaningfully different. After that statistical analysis, ANOVA used to determine which of the variable or variables assigned to the overall difference. A significant time main effect could be attributed to ATG-T $F_{(2.15,73.31)}=5.55, p<.05 \eta^{2}=.084$,
ATG-S $F_{(2.44,83.1)}=11.16, p<.05 \eta^{2}=.127$, and GI-T $F_{(2.74,}$ 93.18) $=9.69, p<.05 \eta^{2}=.187$ subscales. These results mean that there was a significant difference in the measurement that performed different times. There was not a significant difference on GI-S, $F_{(2.53,85.88)}=4.71, p>.05 \eta^{2}=.063$. Another univariate follow-up analysis related with group effect revealed significant differences in ATG-T $F_{(1,34)}=41.56, p<.05 \eta^{2}=.55$, ATG-S $F_{(1,34)}=8.86, p<.05$ $\eta^{2}=.21$, and GI-T $F_{(1,34)}=23.83, p<.05 \eta^{2}=.41$ subscales and GI-S $F_{(1,34)}=7.33, p>.05 \eta^{2}=.18$. These results indicated significant differences in these subscales between experimental and control group favoring experimental group.

Quantitative data results were supported by qualitative data for the question that related with team cohesion. According to results of athletes' two important themes affirmed to improve team cohesion perceptions, those themes were "spending time with team members at outside of the trainings and matches" and "helpful practices to know each other better". Moreover, coach enlightened that the applications are thought to be supportive in terms of team unity, getting the athletes closer and making them understand this is not an individual sport on the contrary it is a team sport.

Table 1. Control (Con) and Experimental (Exp) groups' Pre-Intervention, Post- Intervention, Follow Up tests Questionnaire Descriptive Statistics

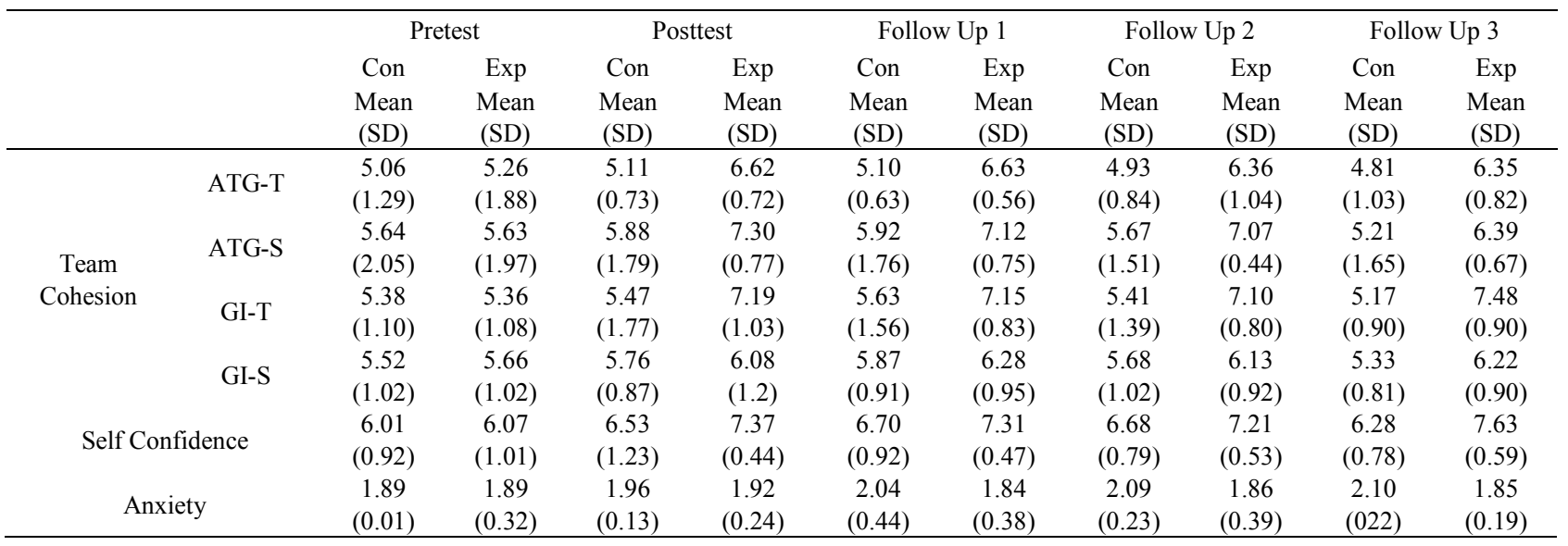

Note: Mean= Arithmetic Average, $\mathrm{SD}=\mathrm{Standard}$ Deviation ATG-T=individual attraction to the group - task; ATG-S=individual attraction to the group - social; GI-T= group integration-task; GI-S= group integration-social

Table 2. Estimated marginal means (Pairwise Comparison Analysis figures) of Team Cohesion between experimental and control group over measurements

\begin{tabular}{|c|c|c|c|c|c|c|c|c|c|c|c|}
\hline & & \multicolumn{2}{|c|}{ Pretest } & \multicolumn{2}{|c|}{ Posttest } & \multicolumn{2}{|c|}{ Follow Up 1} & \multicolumn{2}{|c|}{ Follow Up 2} & \multicolumn{2}{|c|}{ Follow Up 3} \\
\hline & & Con & Exp & Con & Exp & Con & Exp & Con & Exp & Con & Exp \\
\hline & & $\begin{array}{c}\text { Mean } \\
(\mathrm{SD})\end{array}$ & $\begin{array}{c}\text { Mean } \\
(\mathrm{SD})\end{array}$ & $\begin{array}{c}\text { Mean } \\
(\mathrm{SD})\end{array}$ & $\begin{array}{c}\text { Mean } \\
(\mathrm{SD})\end{array}$ & $\begin{array}{c}\text { Mean } \\
(\mathrm{SD})\end{array}$ & $\begin{array}{c}\text { Mean } \\
(\mathrm{SD})\end{array}$ & $\begin{array}{c}\text { Mean } \\
(\mathrm{SD})\end{array}$ & $\begin{array}{c}\text { Mean } \\
(\mathrm{SD})\end{array}$ & $\begin{array}{c}\text { Mean } \\
(\mathrm{SD})\end{array}$ & $\begin{array}{l}\text { Mean } \\
(\mathrm{SD})\end{array}$ \\
\hline \multirow{8}{*}{$\begin{array}{c}\text { Team } \\
\text { Cohesion }\end{array}$} & \multirow{2}{*}{ ATG-T } & 5.05 & 5.26 & 5.11 & 6.62 & 5.10 & 6.63 & 4.92 & 6.36 & 4.81 & 6.36 \\
\hline & & 1.29 & 1.88 & .73 & .68 & .63 & .57 & .84 & 1.05 & 1.03 & 1.04 \\
\hline & \multirow{2}{*}{ ATG-S } & 5.65 & 5.63 & 5.88 & 7.30 & 5.92 & 7.11 & 5.68 & 7.07 & 5.21 & 6.40 \\
\hline & & 2.05 & 1.98 & 1.80 & .78 & 1.77 & .75 & 1.51 & .45 & 1.65 & 1.24 \\
\hline & \multirow{2}{*}{ GI-T } & 5.38 & 5.36 & 5.47 & 7.19 & 5.63 & 7.16 & 5.41 & 7.11 & 5.17 & 7.48 \\
\hline & & 1.10 & 1.09 & 1.77 & 1.34 & 1.56 & .83 & 1.40 & .81 & 1.40 & .86 \\
\hline & \multirow{2}{*}{ GI-S } & 5.53 & 5.66 & 5.76 & 6.08 & 5.87 & 6.28 & 5.69 & 6.13 & 5.32 & 6.22 \\
\hline & & 1.01 & .78 & .75 & .73 & .81 & .67 & .84 & .71 & .81 & .90 \\
\hline
\end{tabular}


Table 3. Estimated marginal means (Pairwise Comparison Analysis figures) of Self Confidence between experimental and control group over measurements

\begin{tabular}{cccccccccccc}
\hline & \multicolumn{2}{c}{ Pretest } & \multicolumn{2}{c}{ Posttest } & \multicolumn{2}{c}{ Follow Up 1 } & \multicolumn{2}{c}{ Follow Up 2 } & \multicolumn{2}{c}{ Follow Up 3 } \\
& Con & Exp & Con & Exp & Con & Exp & Con & Exp & Con & Exp \\
& Mean & Mean & Mean & Mean & Mean & Mean & Mean & Mean & Mean & Mean \\
& (SD) & (SD) & (SD) & (SD) & (SD) & (SD) & (SD) & (SD) & (SD) & (SD) \\
\hline \multirow{2}{*}{ Self Confidence } & 6.01 & 6.07 & 6.53 & 7.38 & 6.70 & 7.63 & 6.69 & 7.71 & 6.28 & 7.64 \\
& .24 & .22 & .22 & .21 & .17 & .16 & .14 & .13 & .17 & .16 \\
\hline
\end{tabular}

Table 4. Estimated marginal means (Pairwise Comparison Analysis figures) of Anxiety between experimental and control group over measurements

\begin{tabular}{cccccccccccc}
\hline & \multicolumn{2}{c}{ Pretest } & \multicolumn{2}{c}{ Posttest } & \multicolumn{2}{c}{ Follow Up 1 } & \multicolumn{2}{c}{ Follow Up 2 } & \multicolumn{2}{c}{ Follow Up 3 } \\
& Con & Exp & Con & Exp & Con & Exp & Con & Exp & Con & Exp \\
& Mean & Mean & Mean & Mean & Mean & Mean & Mean & Mean & $\begin{array}{c}\text { Mean } \\
\text { Mean } \\
\end{array}$ \\
& (SD) & (SD) & (SD) & (SD) & (SD) & (SD) & (SD) & (SD) & (SD) & $($ SD) \\
\hline \multirow{2}{*}{ Anxiety } & 2.00 & 1.90 & 1.96 & 1.93 & 2.04 & 1.84 & 2.10 & 1.86 & 2.10 & 1.96 \\
& 0.57 & 0.53 & .46 & .44 & .98 & .93 & 0.78 & .74 & .50 & 1.47 \\
\hline
\end{tabular}

Self-confidence was at the second rank of PST that had applied to experimental group. This time, a mixed design Analysis of Variance was conducted. A time $\mathrm{x}$ group interaction was found to be significant, $\mathrm{F}_{(2.40,81.57)}=4.34$, $p<.05 \eta^{2}=.11$. Test of time effect was found to be significant, $\mathrm{F}_{(2.40,81.57)}=13.21, p<.05 \eta^{2}=.28$. Test of group effect was found to be significant, $F_{(1,34)}=32.09$, $p<.05 \eta^{2}=.45$. Analysis of the time $\mathrm{x}$ group interaction results introduced that experimental group obtained positive implications about self-confidence. However, results affirmed that control group did not show any meaningful changes about self-confidence.

Self-confidence qualitative question supported the results of quantitative data. Results highlighted that "dealing with problematic situations" "using taught strategies (imagery self-talk) in all possible field" and "thinking more positive within all situations" were the important themes about improving self-confidence. Related with self-confidence question, coach highlighted that he observed a slow but balanced development on athletes' self-confidence perceptions.

Last skill of the PST was Anxiety and to test the effects of it a mixed design analysis of variance was used. Test of time $\mathrm{x}$ group interaction did not found to be significant, $\mathrm{F}_{(2.83,96.24)}=.80, p>.05 \eta^{2}=.023$. Test of group effect did not found to be significant, $\mathrm{F}_{(1,34)}=.92, p>.05 \eta^{2}=.191$. Test of time effect did not found to be significant, $\mathrm{F}_{(2.83,96.24)}=.63, p>.05 \eta^{2}=.018$.

"Learning how to handle mistakes and problematic issues" and "having suspensions about coach's expectations from them and the way he expresses his expectations" were crucial themes related with anxiety in qualitative question. The coach of the team informed that strengthened communication between them supported the athletes to have faith in coach's intention fully.

\section{Discussion}

This part of the study is presented with regard to rank of applied skills and obtained results are discussed in line with the current literature.

Athletes in the experimental group experienced more significant enhancements of their perceptions of team cohesion during the intervention time period compared to athletes in the control group. In other words, athletes who took part in the PST had a meaningful enhancement in their perceptions of team cohesion. Indeed, results show meaningful development - except for GI-S subscale- in three subscales of team cohesion are ATG-T, ATG-S, and GI-T. The enhancement of ATG-T scale shows that implemented PST intervention meaningfully improves athletes' individual perceptions of the importance of being a part of a team and motivations to complete team tasks as well as positively impacts the team's shared ambitions of success. The development of ATG-S shows a meaningful enhancement in the athletes' abilities to have good social interaction. The improvement of GI-T scale shows that employing strategies related to team cohesion significantly enhance athletes' ability to give and receive support from their teammates.

These results can be attributed to multiple factors, including setting initial team goals, receiving the participation of all athletes, applying a PST program that is built upon the missions of every athlete in the field, and lastly organizing and practicing activities in alternative settings. Consistent with the expectations of this study, various research studies indicate significant improvement in team cohesion. Different researchers attribute their results to the realization of the importance of setting common goals. [35, 36] Athletes become better aware of the importance of social interaction, role behavior, coach-athlete communication and team leadership [37], in other studies also it has found that athletes' satisfaction levels were increased by learning and utilizing goal setting interventions, moreover, shared cognition's importance has been informed by the athletes. [30, 38, 39]; Players are better able to act in collaboration and participate in setting team goals. [40] Overall, players come to realize the importance of social interaction, feelings of security, willingness to change and team unity [41, 42].

There was clear evidence of the experimental group 
positively improving their perceptions of self-confidence over the PST time period while the confidence level of the control group remained stable. The positive change in self-confidence shows that implemented psychological strategies are successful in their ability to enhance participants' feelings about living in a more secure environment, performance of motor skills, and ability to behave according to basketball principles and deal with stressful situations. This obtained data could be useful in the future to design an enthusiastic sportive environment, inspire athletes to succeed and work as a team and allow them to improve their focus within athletic settings.

The results of the current study with regard to the significant increase in self-confidence have been also indicated by various researches. Results of the studies are related to different phenomena such as cognitive behavioral interventions (motivation, self-talk, etc) and directing attentional focus $[11,43]$. Significant increases in self-confidence will lead to improvement in the management of the ability to concentrate when facing errors those committed by athletes and when accepting a negative assessment (from others or themselves) about their athletic performances [44], higher winning percentages, better attentional focus, $[45,46,47]$ optimism and ability to eliminate distractions $[48,49,50]$; Athletes experience an increase in their ability to control inner dialogue and a decrease in the occurrence of interfering thoughts $[21,51$, 52].

The final factor that PST impacted is anxiety. The obtained results indicate that athletes in the experimental group did not have significant declines in their anxiety level. The control group, which did not take any intervention, also did not experience a significant decrease in anxiety levels. According to implications of the study this unexpected result occurred because of factors such as insufficient time of anxiety interventions $[53,54,55]$ and the age of participants. [56] Athletes in the age range of $13-16$ age years old experience higher anxiety levels than normal. This is not the most operative time to initiate a PST program that can lower their anxiety levels. The PST program is only two weeks during which three different relaxation techniques are employed as well as a mental imagery program $[57,58,59]$. Even though there are reasons to view the positive results with caution, there are also reasons to be optimistic about the findings. Although the results revealed decrements in the experimental group, the numbers were not statistically significant.

\section{Conclusions}

From an historical perspective, it is clear that the field of sport psychology has always maintained an interest in psychological preparation. While this hone in the performance of athletes began with the research of personality characteristics of elite athletes, it consequently edged to the theory and practice of psychological skill training programs. In this study, it is aimed to examine the impact of six weeks psychological skills training program (PST) based on cognitive-behavioral conceptual framework on the team cohesion, confidence, and anxiety of an intact team. Initially, PST made meaningful differences on experimental group participants' perceptions about team cohesion and self-confidence. However, PST intervention with basketball team did not make meaningful differences on experimental group athletes' anxiety levels. Third, there were meaningful differences between experimental and control group athletes on implied psychological skills all over time of study.

The qualitative part of this study added appreciable depth to understanding how different athletes experience selected psychological skills. One of the strength points of the study was its applicability to other areas of the athletes' lives. As can be understood from their subjective evaluations, athletes mentioned how they felt the program helped them in their studies, relations with others, and approach to life in general. They also mentioned how they valued the interventions sessions and enjoyed knowing with each other closer and with a researcher to learn concepts and techniques and to express feelings about tensions in their sports and real life situations.

The present study has some limitations that need to be taken into account when considering its contributions. In this study PST was performed on the middle season of basketball league. As mentioned above scientific studies and literature about psychological skill training offer the pre-season or off season to start PST programs. Present study's intervention duration was six weeks. There are some studies with same duration but sport psychology literature advice to design at least 3 months and longer duration for psychological skill training to find meaningful difference in findings. Also, according to qualifications of team environment and opinions of other staff (coach, manager, etc) different skills (concentration, motivation, pep-talk, coping and stress appraisal etc.) can use to reveal affects of PST on personal and performance development in sport environment. Finally, other constructional similar parameters like psychological well-being, mental preparedness, motor learning and motor performance, etc. would be useful to examine in future studies.

\section{REFERENCES}

[1] Moran, P. A., (2006). The Psychology of Concentration in Sport Performers: A Cognitive Analysis, Routledge, New York, NY 10017, USA.

[2] Vealey, R. (2007). Mental skills training in sport. In G. Tenenbaum \& R. Eklund (Eds.), Handbook of sport psychology (3rd ed., pp. 287-309). Chichester: John Wiley and Sons.

[3] Ravizza, K. (2001). Increasing awareness for sport 
performance. J.M. Williams (Ed.), Applied sport psychology: personal growth to peak performance (4th ed.), Mayfield, Mountain View, CA (2001), pp. 179-189

[4] Bacon, T. (1989). The planning and integration of mental training programs, Sports: Science Periodical on Research \& Technology in Sport: Vol. 10 Issue 1. p. 1-8.

[5] Vealey, R. S. (1994). Current status and prominent issues in sport psychology interventions. Medicine and Science in Sports and Exercise, 26, 495-502.

[6] Whelan, J.P., Mahoney, M.J., \& Meyers, A.W. (1991). Performance enhancement in sport: A cognitive behavioral domain. Behavior Therapy, 22, 307-327.

[7] Weinberg, R.S., \& Williams, J.M. (2001). Integrating and implementing a psychological skills training program. In J. M. Williams (Ed.), Applied sport psychology: Personal growth to peak performance (4th ed., pp.347-377). Mountain View, CA: Mayfield Publishing.

[8] Weinberg R.S. \& Gould, D. (2007). Foundations of sport and exercise psychology. Champaign, IL: Human Kinetics.

[9] Wann D., Church B., (1998) A Method for enhancing the psychological skills of track and field athletes, Murray State University.

[10] Calmels, C., Arripe-Longueville, F. (d'), Fournier, J. F., \& Soulard, A. (2003). Mental skills among elite female gymnasts: An exploration of the relative influence of mental training and natural learning experiences. International Journal of Sport and Exercise Psychology, 1, 327-352.

[11] Morgan, T. K. (2006). A Season-Long Mental Skills Training Program for Collegiate Volleyball Players, Unpublished doctoral dissertation, University of Tennessee.

[12] Paiva, M. (2006). An examination of the relationship between mental skills training and bowling performance. Unpublished doctoral dissertation, University of Capella.

[13] Thelwell, R.C. \& Greenlees, I.A. (2001). The effects of a mental skills training package on gymnasium triathlon performance. The Sports Psychologist, 15, 127-141.

[14] Ritz, N., (2012). The effects of mental preparation for distance runners, Marathon \& Beyond, Vol: 2, p: 120-130.

[15] Horn, T.S. (2002) Advances in Sports Psychology (pp 459-493). Champaign, Ilinios; Human Kinetics.

[16] Greenspan, M., \& Feltz, D. L. (1994). Psychological interventions with athletes in competitive situations: A review. The Sport Psychologist, 3, 219- 236.

[17] Meyers, A. W., Whelan, J. P., \& Murphy, S. M. (1996). Cognitive behavioral strategies in athletic performance enhancement. In M. Hersen, R. M. Miller, \& A. S. Belack (Eds.), Handbook of behavior modification (Vol. 30, pp. 137 - 164). Pacific Grove, CA: Brooks/Cole.

[18] Bruner, M. W. \& Spink, K. S. (2011). Effects of team building on exercise adherence and group task satisfaction in a youth activity setting, Group Dynamics: Theory, Research, and Practice, Vol. 15, No. 2, 161-172.

[19] Crace, K. R. and Hardy, C. J. (1997). Individual values and the team building process. Journal of Applied Sport Psychology, Special issue: Team building, 9, 41-60.
[20] Fournier, JF., Calmels, C., Durand-Bush, N., \& Salmela, JH. (2005). Effects of a season-long PST program on gymnastic performance and on psychological skill development. International Journal of Sport and Exercise Psychology, 3, 59-77.

[21] Gucciardi, D.F., Gordon, S., \& Dimmock, J.A. (2009). Evaluation of a mental toughness training program for youth-aged Australian footballers: I. A quantitative analysis. Journal of Applied Sport Psychology, 21, 307-323.

[22] Krane, V., \& Williams, J. M. (2006). Psychological characteristics of peak performance. In J. M. Williams (Ed.), Applied sport psychology: Personal growth to peak performance (pp. 207-227). New York: McGraw-Hill.

[23] Orlick T. \& McCaffrey, N. (1991). Mental training with children sport life. The Sport Psychologist, 5, 322-334.

[24] Sheard, M., \& Golby, J. (2006). Effect of a psychological skills training program on swimming performance and positive psychological development. International Journal of Sport and Exercise Psychology, 4, 149-169.

[25] Yukelson, D. (2001). Communicating effectively. In J. M. Williams (Ed.) Applied Sport Psychology: Personal Growth to peak performance ( $4^{\text {th }}$ ed., pp: 135-149) CA: Mayfield.

[26] Öcel, H. (2002). Takım sporu yapan oyuncuların kollektif yeterlik, öz yeterlik ve sargınlık ile başarı algı ve beklentisi arasındaki ilişkiler. Yayımlanmamış yüksek lisans tezi. Hacetepe Üniversitesi. Ankara.

[27] Engur, M., Tok., S., Tatar, A., (2006). Durumluluk ve surekli sportif guven envanterlerinin turkceye uyarlanmas1 (adaptation of state and trait sport confidence scales). 9. Uluslararas1 Spor Bilimleri Kongresi Bildiri Kitab1, P-331, Muğla, 3-5 Kasım.

[28] Öner N. \& Le Compte, A. (1983). Durumluk-Sürekli Kayg1 envanteri, Boğaziçi Üniversitesi Matbaası, İstanbul

[29] Singer, R. N., Murphy, M., \& Tennant, L. K. (1993). Epilouge. In R. N. Singer, M. Murphy, M., \& L. K. Tennant (Eds.) Handbook of research in sport psychology (pp. 933-938). New York: McMillan.

[30] Carron, A.V., Widmeyer, W.N. and Brawley, L.R. (1985). The development of an instrument to assess cohesion in sport teams: the Group Environment Questionnaire. Journal of Sport Psychology, 7, 244 - 266.

[31] Vealey, R.S. (1988). Future directions in psychological skills training. The Sport Psychologist, 2, 318-336.

[32] Spielberger, C. D., Gorsuch, R. L. \& Lushene, R. E. (1970). S.T.A.I. Manual for the State-Trait Anxiety Inventory. Palo Alto, CA : Consulting Psychologists' Press.

[33] Thomas, J. R., \& Nelson, J. K. (2001). Research methods in physical activity (4th ed.). Champaign, IL: Human Kinetics.

[34] Glasser, B. \& Strauss, A. (1967). The discovery of grounded theory: Strategies for qualitative research. Chicago: Aldine.

[35] Cogan, K. D., \& Petrie, T. A. (1995). Sport consultation: An evaluation of a season-long intervention with female collegiate gymnasts. The Sport Psychologist, 9, 282 - 296.

[36] Senécal, J., Loughead, T.M. \& Bloom, G. A. (2008). A season-long team-building intervention: examining the effect of team goal setting on cohesion, Journal of Sport \& Exercise 
Psychology, 2008, 30, 186-199.

[37] Stevens, D.E., \& Bloom, G.A. (2003). The effect of team building on cohesion. Avante, 9, 43-54.

[38] Burton, D. (1989). Winning isn't everything: Examining the impact of performance goals on collegiate swimmers' cognitions and performance. The Sport Psychologist, 2, 105-132.

[39] Cohn, P. J., Rotella, R. J., \& Lloyd, J. W. (1990). Effects of a cognitive-behavioral intervention on the preshot routine and performance in golf. The Sport Psychologist, 4, 33-47.

[40] Brawley, L.R., Carron, A.V., \& Widmeyer, W.N. (1993). The influence of the group and its cohesiveness on perceptions of group goal-related variables. Journal of Sport \& Exercise Psychology, 15, 245-260.

[41] Vazne, Z., (2008). Structure of the factors of psychological and physical condition in youth basketball. 2-nd International scientific conference. Current Issues and New Ideas in Sport Science. Abstracts. Lithuania, Kaunas, 149-151.

[42] Voight, M., \& Callaghan, J. (2001). A team building intervention program: Application and evaluation with two university soccer teams. Journal of Sport Behavior, 24, 420-431.

[43] Zinsser, N., Bunker, L. \& Williams, J. M. (1999) Cognitive techniques for building confidence and enhancing performance. In Williams, J. M. (1998) Applied Sport Psychology: Personal growth to peak performance ( $3^{\text {rd }}$ ed.). Mountain View, CA: Mayfield

[44] Olmedilla, A., Ortega, E., González, J., \& Serpa, S. (2015). Psychological training in sailing: Performance improvement for the Olympic classification phase. Universal Journal of Psychology, 3(4), 122-131.

[45] Daw, J. \& Burton, D. (1994). Evaluation of a comprehensive psychological skills training program for collegiate tennis players. The Sport Psychologist, 8, 37-57.

[46] Garza, D. L., \& Feltz, D.L. (1998). Effects of selected mental practice on performance, self-efficacy, and competition confidence of figure skaters. The Sports Psychologist, 12, $1-15$.

[47] Gipson, M., Mckenzie, T., \& Lowe,S. (1989) The sport psychology program of the USA women's national volleyball team. The Sport Psychologist, 3, 330-339

[48] Edwards, D.J. \& Steyn, B.J.M. (2008). Sport psychological skills training and psychological well-being, South African Journal for Research in Sport, Physical Education and
Recreation, 30 (1): 15-28.

[49] Gonzalez, S. P., Metzler, N. J. \& Newton, M. (2011). The Influence of a Simulated 'Pep Talk' on Athlete Inspiration, Situational Motivation, and Emotion, International Journal of Sports Science \& Coaching, Vol 6, Num: 3, $445-454$.

[50] Hanton, S., \& Jones, G. (1999). The effects of a multimodal intervention program on performers: II. Training the butterflies to fly in formation. The Sport Psychologist, 13, $22-41$.

[51] Hatzigeorgiadis, A., Theodorkis, Y., \& Zourbanos, N. (2004). Self-talk in the swimming pool: The effects of self-talk on though content and performance on water-polo tasks. Journal of Applied Sport Psychology, 16,138-150.

[52] Perkos, S., Theodorakis, Y., \& Chroni, S. (2002). Enhancing performance and skill acquisition in novice basketball players with instructional self-talk. The Sport Psychologist, 16, 368-383.

[53] Crocker, P. R. E., Alderman, R. B., \& Smith, F. M. R. (1988). Cognitive affective stress management training with high performance youth volleyball players: Effects on affect, cognition, and performance. Journal of Sport and Exercise Psychology, 10, 448- 460.

[54] Cox, R. H., (2007), Sport psychology: Concepts and applications, McGraw Hill International edition, Columbia.

[55] Hamstra, M. S., Burke, K. L., Joyner, B. A., \& Hardy, C. H. (2004). An analysis of mental training programs' influences on intercollegiate female athletes' selected psychological skills: a single-subject / qualitative design, Journal of Excellence, 9, 34 -46.

[56] McCarthy, P. J., Jones, M. V., Harwood, C. G., \& Oliver S. (2010). What do young athletes implicitly understand about psychological skills?. Journal of Clinical Sport Psychology, $4,158-172$

[57] Navaneethan B. \& Rajan S. (2010). Effect of progressive muscle relaxation training on competitive anxiety of male inter collegiate volleyball players,

[58] Griciute, A. \& Cibulskaite, R. (2010). Peculiarities of state and trait anxiety and social competence among athletes, physically active and non-athletes extramural students. Education Physical Training Sport. P: 45-52

[59] Seabourne, T. G., Weinberg, R. S., Jackson, A., \& Suinn, R. M. (1985). Effect of individualized, nonindividualized, and package intervention strategies on karate performance. Journal of Sport Psychology, 7, 40-50. 